\title{
A productivity analysis of Iranian industries using an additive data envelopment analysis
}

\author{
Mohammad Rahmani ${ }^{*}$
}

${ }^{a}$ Assistant Professor, Buali Sina University, Hamedan, Iran

\begin{tabular}{|c|c|}
\hline CHRON I C L E & A B S T R A T \\
\hline $\begin{array}{l}\text { Article history: } \\
\text { Received: June 1, } 2016 \\
\text { Received in revised format: No- } \\
\text { vember } 16,2016 \\
\text { Accepted: December } 27,2016 \\
\text { Available online: } \\
\text { December 27, } 2016 \\
\text { Keywords: } \\
\text { Productivity } \\
\text { Data Envelopment Analysis } \\
\text { (DEA) } \\
\text { Additive model } \\
\text { Analytical Hierarchy Process } \\
\text { (AHP) }\end{array}$ & $\begin{array}{l}\text { Monitoring productivity of economic sections of a country would be an important step towards } \\
\text { a reliable planning. Developmental decisions based on weaknesses and strengths will guarantee } \\
\text { effectiveness, since it will lead to an effective allocation of resources. Among performance } \\
\text { measurement approaches, the Data envelopment analysis (DEA), is a model that measures and } \\
\text { reports excesses and deficits via analyzing input and output aspects. Aid of this exact and dis- } \\
\text { criminating measurement, a proper DEA model applied in this study, can be an efficient instru- } \\
\text { ment in fields which need scrutinizing analyses. Industrial productivity analysis of a country is } \\
\text { one of such fields. This study applies an instrument developed based on the DEA approach for } \\
\text { measuring the industrial productivity of the country. The results obtained, may pave the path for } \\
\text { policy-making for economic growth in such a way that enables an effective resources allocation. } \\
\text { The applied instrument is a weighted additive model, for which a sufficient number of yearly } \\
\text { periods are considered as decision making units (DMUs). The weights included in the model } \\
\text { are driven by executing an analytical hierarchy process. After running the model the results } \\
\text { demonstrate excesses and deficits in each DMU which can illuminate not only the past perfor- } \\
\text { mance but also help to plan for the future policies. }\end{array}$ \\
\hline
\end{tabular}

(C) 2017 Growing Science Ltd. All rights reserved.

\section{Introduction}

Industry, as one of the economic sections of any country, has been changed both in terms of software dimensions (frameworks, programs, regulations and laws) and hardware dimensions (development, financial and credit institutions). So identification of this section, that is necessary for describing existing situation and analysis and planning for desired state, requires a multi-faceted and discriminating instrument (Amann, 2002). The importance of such an instrument, resides in the dynamic nature of the industry section and as a result the necessity of dynamism of the instrument. Productivity analysis of the industry section should bring vision for decision makers and policy developers to illuminate the future path. This analysis, especially if clarify weaknesses and strengths of the industry system in different time periods, would have a key value in identifying the realized (past) situation and more importantly, developing future strategies (Hitomi, 2004). In this way, this research aims at constructing a model that 
helps a productivity analysis that provides useful managerial information for identification of different dimensions and strength and weakness points in performance and guidelines for future operations as well. For achieving such an instrument, the data envelopment analysis (Charnes et al., 2013) approach will be exerted in a model that while including multiple inputs and outputs, specifies slacks. Discriminate features of the model are as follows:

1. Focusing the productivity of the industry section as one of the economic sections, not on individual firms

2. Considering both inputs decreasing and outputs increasing as productivity enhancement leverages.

3. Weights will be allocated in the model that is yielded via analytical hierarchy process (AHP) (Saaty, 1990). These will act as preliminary information about the different measures.

\section{Research background}

The industry system of a country reacts to any changes under different conditions specially demand structure, technology opportunities, and political regimes of that country. For instance new comers enter and start to grow and develop. Others leave the ground, market share shifts between producers that are different regarding technology, managerial expertise and profit (Li \& Lin, 2016).

Industry's changes during time can be related to three forces (factors); Changes in technology and demand patterns that provokes products development and entry of new producers in some sections and products diminishment and exit of some producers in other sections. The entry and exit patterns as a result of changes in industrial patterns in a country from producing low-technology products to hightech products is an example of long-term transformations (Wu, 2001).

The second factor is short-term or periodic variations in demand such as those driven by changes in macroeconomic conditions. Of course this factor is not the case where the hidden costs are barriers to industry entrance. But it will be an important factor for industrial transformations in an atmosphere that temporal entry and exit can be profitable.

The third factor is substitution of low-efficiency producers by more efficient producers of the same industry. When different producers in an industry, are not the same regarding profitability and productivity, market forces cause modifications in producers' structure; efficient producers dominate and discard non-efficient producers.

Each of these industrial transformations can be potentially useful. When the efficiency level is different among different industrial firms, reallocation of resources by transformational processes can bring productivity growth. Also if changes in demand pattern reduce profitability in one section relative to another section, movement of resources between these sections will finally lead to total welfare of the society. Even if the resources are not moved between sections, the entrance and exit phenomena and reallocation of market share can provoke competitive forces, and enhance allocation efficiency through constraining the producers' power in the market. Of course one should consider the costs related to movement of resources and lost revenues because of factors that are lost temporarily.

\section{Literature Review}

\subsection{Productivity and Industrial Performance}

Productivity is an economic notion and refers to the proportion of outputs to inputs. Efficiency that is a notion based on physics is also a ratio of output to input that is measured by physical units. When just one input and output are included in the production process, then the productivity ratio can be represented in physical units that will be a ratio representing the efficiency measure as well. In the case of multiple inputs and outputs, however, these non-homogenous elements of inputs and outputs should be consolidated via value or cost weights. What is yielded, will be an economic ratio not a physical one. 
When the price or cost of one unit of output or input changes, the productivity ratio may change even though the physical units that form the ratio remain unchanged (Norsworthy \& Jang, 1992: 8). Productivity is affected and formed by many forces. The total factor productivity (TPM) reflects the effectiveness of deformational policies, the response of institutions to changes in competition, and other dimensions of market structure, learning effects, benefits of executing new equipment or technical knowledge and organizational skills, and the effect of societal, political, or organizational factors on innovation. Exact determination of the cause of productivity trend is difficult. Moreover, the changes in total productivity, encompasses different types of economic behaviors. Given these, knowing the trend of total factor productivity in the industry of a country would be useful, and yields valuable information and wisdom. Industrial productivity trends, provides measure for detailed and total performance that enables the analyzer to do rapid comparisons between countries through investigating transformation during time periods, and hence helps understanding the trend of growth and development [or decline] of a country (Jefferson et al., 1996).

\subsection{Factors affecting technology and industrial productivity}

Any changes in quantity or quality of inputs and outputs or processes used in transforming inputs to outputs are classified as technological change. As mentioned before, technological changes affect TPM. Thus if technologic changes are not measured, one cannot measure their effect on TPM. A series of phenomena outside factory, firm, or industry can affect production technology and productivity; national policies, international competition and macroeconomic phenomena may affect technological transformations and productivity (Norsworthy \& Jang, 1992).

\subsection{Analysis of Productivity Changes using Border Line Methods}

A dozen of instruments are presented in the literature for analyzing the changes of technical efficiency. The Scale efficiency change approach is one of them, which are founded on geometric mean of scale efficiency changes. This method has arisen many discussions. The main critique on this method is that in the case of changes in scale efficiency, what can be resulted about production technology (Coelli et al., 2005: 293). In another approach, the productivity effect is divided into two components; efficiency and technological change. The aim here is to determine managers' role or technology level in final performance (Fuentes \& Lillo-Banuls, 2015). Productivity measurement based on radial DEA models with one fixed input is another approach in this field. In this approach, which includes a mixed action, two autonomous source are considered that include change in technical efficiency and technical change. Technical change itself is divided into other components. Aggregate productivity index is expressed via geometric mean of two periods and periodic distance function (Karagiannis \& Lovell, 2016).

\subsection{Concepts and Applications of Data Envelopment Analysis (DEA)}

Data envelopment analysis has been designed principally for studying relative efficiency of different companies or managerial units, with the assumption that they have a "best technology" that is common among these units. This method lets for comparison among companies based on efficiency level in exploiting inputs for producing outputs given the existing technology. The econometric production function approach also takes the technology as fixed and the companies are evaluated based on their positions regarding a fixed production function. As opposed to parametric approaches that their goal is optimization of a regression plane through data, the DEA approach aims at optimizing each observation via calculation of a border line determined by efficient decision units.

\subsection{Basic Models of DEA}

Data envelopment analysis is referred to a set of concepts and methodologies that are represented in the form of the following models: 
1- The CCR ratio model: presents total efficiency and identifies sources and amounts of inefficiency.

2- This model differentiates technical and scale inefficiency through the following ways:

a. Estimating net technical efficiency by a determined measure of operations,

b. Identification of increasing, decreasing, or fixed return on scale.

3- Coefficient models

4- Additive model and additive developed model

While each of these models consider managerial and economic issues and provide useful results, they are different at direction. These models also are in close relationship with the aforementioned disciplines (management and economics). Hence, they may concentrate on increasing, decreasing, and fixed economies of scale as discussed in economics and have been generalized to multiple outputs here.

The models can determine an efficient border that may be linear, linear-logarithmic or Cap-Daglas that have been generalized to the multiple inputs-outputs case. These models can concentrate on diminishing inputs or increasing outputs for achieving efficiency.

\section{Model Representation, Data and Analysis Method}

Productivity evaluation should yield useful managerial information for identification of various dimensions and strengths and weaknesses in performance and provide guidelines for future operations. The DEA methodology presents effective performance goals for inefficient operations. The basic CCR model focuses on improvement in a specific direction. In order to concurrent consideration of possibility of both inputs savings and outputs enhancement, in this study an additive model has been formed the center of the analysis, which concentrates on Pareto-Koopmans production functions. The initial additive DEA model exerts equal final values for inputs and outputs non-zero slacks. So one should be careful in selecting inputs and outputs evaluation units. In order to prevent improper consolidating nonhomogenous measures, some initial information may be needed. In this regard, managerial experience and professional judgments that have a special role in productivity analysis may be useful. Hence the initial additive DEA model is modified and represented as the additive weighted CRS model as follows:

$$
\max \sum_{i=1}^{m}{w_{i}}^{-} s_{i}+\sum_{r=1}^{s} w_{r}{ }^{+} e_{r}
$$

subject to

$$
\begin{array}{ll}
\sum_{j=1}^{n} \lambda_{j} x_{i j}+s_{i}=x_{i 0} & i=1,2,3, \ldots, m \\
\sum_{j=1}^{n} \lambda_{j} y_{r j}-e_{r}=y_{r 0} & r=1,2,3, \ldots, s
\end{array}
$$

where $\mathrm{x}_{\mathrm{ij}}$ and $\mathrm{y}_{\mathrm{rj}}$ are input and output quantities and $\mathrm{w}_{\mathrm{i}}^{-}$and $\mathrm{w}_{\mathrm{r}}{ }^{+}$are the weights obtained via professional judgments.

Decision making unit $\left(\mathrm{DMU}_{0}\right)$ will be regarded as efficient if the optimum amount obtained from the model equals zero. If not, a non-zero optimum amount of $s_{i}$ represents the excess consumption of the related input and $e_{r}$ represents the output deficiency. In this way the solution of the model yields the information regarding possible modifications in each input and output of each decision making unit. Therefore, the model is a proper instrument for determining objectives for inefficient units based on initial information about inputs and outputs modifications. The dual model will be as follows: 
$\min \sum_{i=1}^{m} v_{i} x_{i 0}-\sum_{r=1}^{s} u_{r} y_{r 0}$

subject to

$$
\begin{aligned}
& \sum_{i=1}^{m} v_{i} x_{i 0}-\sum_{r=1}^{s} u_{r} y_{r 0} \geq 0 \quad j=1, \ldots, n \\
& v_{i} \geq w_{i}^{-}, \quad u_{r} \geq w_{i}^{+}
\end{aligned}
$$

Therefore weights determined for modification of inputs and outputs are lower limits for coefficients. Hence each set of weights that represent different evaluation system, may lead to different performance objectives for inefficient units. Off course it should be considered that the additive weighted model would not necessarily provide result different from that of its initial model, specially results of these two models are not different regarding classifying the units as efficient and inefficient.

\subsection{Data and Weights in the Model}

Selecting relevant and comprehensive inputs and outputs is important because performing an effective analysis requires including indices in analysis that cover various performance aspects. As per this, after studying the literature and related previous studies on other countries and interviews with experts and feasibility of data access, the following input and output measures were selected for analysis: inputs include manpower, remuneration, capital, Inputs value and outputs include outputs value, and value added.

The weights of the data in the model were determined via analytical hierarchy process (AHP) (Saaty, 1990). The input and output factors included in AHP, were modified as per availability of the data. The final modified weights are as in the Table 1.

\section{Table 1}

Weights of the inputs and output factors

\begin{tabular}{lccc}
\hline Inputs & Weights & Outputs & Weights \\
\hline Manpower & 0.35138 & Outputs value & 0.366217 \\
Remuneration & 0.215914 & Value added & 0.633783 \\
Capital & 0.134742 & & \\
Inputs value & 0.297964 & & \\
\hline
\end{tabular}

\section{Results}

As per the explanations presented in the productivity analysis section, the weighted additive CRS model was the basis for achieving necessary data for the analysis. We discussed about the model and the weights exerted in it and the way they were acquired. After the model was designed and solved using the required data, the results are given in Table 2.

The results show that 8 DMUs (38\%) obtain to a zero optimum value of objective function so considered as efficient. The remaining 13 DMUs encompass either outputs deficiencies or inputs excesses. Theses "inefficient" units and the pertinent inputs excesses and outputs deficiencies are shown in the Table 3. 
Table 2

The results of the weighted additive CRS model

\begin{tabular}{lll}
\hline DMUs & Year & Slack (Sum of inputs excesses and outputs deficiencies) \\
\hline 1 & 1980 & 400.4820 \\
2 & 1981 & 0 \\
4 & 1982 & 211.1057 \\
5 & 1983 & 525.2411 \\
6 & 1984 & 129.7982 \\
7 & 1985 & 162.6443 \\
8 & 1986 & 213.5913 \\
9 & 1987 & 0 \\
10 & 1988 & 0 \\
11 & 1989 & 0.1588 \\
12 & 1990 & 985.8651 \\
13 & 1991 & 0 \\
14 & 1992 & 0 \\
15 & 1993 & 50.1437 \\
16 & 1994 & 0 \\
17 & 1995 & 0 \\
18 & 1996 & 1585.7460 \\
19 & 1997 & 838.3354 \\
20 & 1998 & 14.9361 \\
21 & 1999 & 1648.1360 \\
\hline
\end{tabular}

Table 3

Inefficiency sources and amounts in inefficient years

\begin{tabular}{|c|c|c|c|c|c|c|c|c|c|c|}
\hline \multirow[t]{2}{*}{ DMUs } & \multirow[t]{2}{*}{ Year } & \multicolumn{5}{|c|}{ Inputs excesses } & \multicolumn{4}{|c|}{ Outputs deficiencies } \\
\hline & & Labor & Remuneration & Energy & $\begin{array}{l}\text { New in- } \\
\text { vestments }\end{array}$ & $\begin{array}{l}\text { Inputs } \\
\text { value }\end{array}$ & $\begin{array}{l}\text { Products } \\
\text { value }\end{array}$ & $\begin{array}{l}\text { Value } \\
\text { added }\end{array}$ & $\begin{array}{c}\text { Outputs } \\
\text { value }\end{array}$ & Exports \\
\hline 1 & 1980 & 200.1053 & 35.1784 & 3.9384 & & & & 536.4057 & 554.7814 & 35.8055 \\
\hline 3 & 1982 & 82.4361 & 24.0815 & & 7.8403 & & & 317.5254 & 262.5253 & 9.6567 \\
\hline 4 & 1983 & 22.4937 & 63.1523 & & 16.6044 & & & 255.1052 & 1948.5280 & 6.3645 \\
\hline 5 & 1984 & & 86.2008 & & 11.4570 & & & 220.9728 & 153.9022 & 7.2665 \\
\hline 6 & 1985 & 197.5391 & 151.6879 & & 2.8412 & & & 97.0833 & 151.8347 & \\
\hline 7 & 1986 & 202.1283 & 156.4944 & & & & & 196.2517 & 211.6886 & \\
\hline 10 & 1989 & & 1 & & & & & & & 35.8055 \\
\hline 11 & 1990 & & & & & & & 2701 & & \\
\hline 14 & 1993 & & & & & & & & & 220.7999 \\
\hline 16 & 1995 & & & 20.3128 & & 1437.9220 & 1024.8820 & 2375.688 & 950.6042 & \\
\hline 17 & 1996 & 42.3386 & & & 371.0641 & 315.7585 & 1359.1910 & 895.8713 & 581.6128 & \\
\hline 18 & 1997 & & 16.1683 & & 117.9740 & & & & 3.2119 & \\
\hline 19 & 1998 & & 1049.1840 & & 1427.0210 & & 1646.0210 & 1731.7190 & 1736.415 & 61.0707 \\
\hline
\end{tabular}

\subsection{Reference sets}

Results obtained by solving the model, determined the reference sets for inefficient units. These sets accompanied by their weights will be useful in benchmarking. Table 4 presents the reference sets of the inefficient units and their corresponded weights.

\section{Conclusion}

This study aimed at analyzing the strengths and weaknesses of the performance of Iranian industry section and investigating various dimensions of its productivity during a 21 year period. Principally, knowing about the past and present performance is considered as a necessity for developing future strategies, since this exploration highlights the paths for improvements. The results obtained from the additive model demonstrated that 8 DMUs (years) that means $38 \%$ of them were identified as "efficient" and the remaining 68\% were "inefficient" with some excesses (deficiencies) in inputs (outputs). Most of the inefficient years are in the period of difficulties in the country and from 1987 later on, we 
witness a growth in productivity. This is highlighted since 1989 later on; from this year we see just two cases of slack in "value added" and "exports" outputs with amounts of 2701 and 220.7999 retrospectively in 1988 and 1993. Later on we witness an efficient performance if the industry till the year of 1994.

\section{Table 4}

Reference sets for inefficient units and their corresponded weights

\begin{tabular}{|c|c|c|c|c|}
\hline \multirow{2}{*}{$\begin{array}{c}\text { Inefficient } \\
\text { DMUs }\end{array}$} & \multirow{2}{*}{ Year } & \multicolumn{3}{|c|}{ Reference set } \\
\hline & & Decision making unit & Year & Corresponded weight \\
\hline \multirow{3}{*}{1} & \multirow{3}{*}{1980} & 4 & 1983 & 0.0851 \\
\hline & & 8 & 1987 & 0.1934 \\
\hline & & 9 & 1988 & 0.138 \\
\hline \multirow{3}{*}{3} & \multirow{3}{*}{1982} & 2 & 1981 & 0.7532 \\
\hline & & 8 & 1987 & 0.0935 \\
\hline & & 11 & 1990 & 0.0354 \\
\hline \multirow{3}{*}{4} & \multirow{3}{*}{1983} & 2 & 1981 & 0.9594 \\
\hline & & 8 & 1987 & 0.07 \\
\hline & & 11 & 1990 & 0.0334 \\
\hline \multirow{4}{*}{5} & \multirow{4}{*}{1984} & 2 & 1981 & 1.0465 \\
\hline & & 8 & 1987 & 0.0612 \\
\hline & & 10 & 1989 & 0.0185 \\
\hline & & 11 & 1990 & 0.0331 \\
\hline \multirow{4}{*}{6} & \multirow{4}{*}{1985} & 2 & 1981 & 0.1641 \\
\hline & & 8 & 1987 & 0.0396 \\
\hline & & 9 & 1988 & 0.061 \\
\hline & & 10 & 1989 & 0.3459 \\
\hline \multirow{5}{*}{7} & \multirow{5}{*}{1986} & 4 & 1983 & 0.005 \\
\hline & & 8 & 1987 & 0.0674 \\
\hline & & 9 & 1988 & 0.03569 \\
\hline & & 10 & 1989 & 0.0786 \\
\hline & & 11 & 1990 & 0.0339 \\
\hline 10 & 1989 & 10 & 1989 & 1 \\
\hline 11 & 1990 & 11 & 1990 & 1 \\
\hline 14 & 1993 & 14 & 1993 & 1 \\
\hline \multirow{4}{*}{16} & \multirow{4}{*}{1995} & 8 & 1987 & 0.3321 \\
\hline & & 12 & 1991 & 0.2581 \\
\hline & & 15 & 1994 & 0.2583 \\
\hline & & 21 & 2000 & 0.2037 \\
\hline \multirow{3}{*}{17} & \multirow{3}{*}{1996} & 8 & 1987 & 0.1701 \\
\hline & & 15 & 1994 & 0.5088 \\
\hline & & 21 & 2000 & 0.27755 \\
\hline \multirow{6}{*}{18} & \multirow{6}{*}{1997} & 8 & 1987 & 0.0032 \\
\hline & & 12 & 1991 & 0.0131 \\
\hline & & 14 & 1993 & 0.0112 \\
\hline & & 18 & 1996 & 0.9593 \\
\hline & & 20 & 1999 & 0.0091 \\
\hline & & 21 & 2000 & 0.0111 \\
\hline \multirow{3}{*}{19} & \multirow{3}{*}{1998} & 12 & 1991 & 0.3815 \\
\hline & & 20 & 1999 & 0.3995 \\
\hline & & 21 & 2000 & 0.2293 \\
\hline
\end{tabular}

The inefficiency rhythm of the industrial performance of the country starts again in 1995, and continues till 1998 with some variations in excesses (slacks) in inputs (outputs). The last years of the period are also classified as efficient. The "inputs value" is the input factor with the least frequency regarding excess amount among inefficient years; only during 1995 and 1996 we see an excess in this input. While the "manpower" and "remuneration" inputs showed considerable amounts of excess during 1980 to 1987. In most of the years with inefficient performance, a considerable amount of "value added" and "outputs value" was attainable. Especially during 1980 and 1982 to 1986 we witness a slack in these outputs continuously. The amount of "new investment" input was not considerable. Weakness in this input that is evident since 1982 starts an improvement after the year 1983 so that we no longer find an 
excess in this input in year 1987. But from 1996 weakness in this input is highlight. These transformations can be related to irregular utilization of capital due to special conditions of the country at that time that is improved with more control since 1987. However because of insufficient control of the government on considerable section of the industry (governmental industries), excess capital affects the industry negatively again during the years 1996 to 1998. The high amount of excess in "manpower" can be related to the high population of job-seekers in work market of the country and under-optimal utilization of employed manpower. Limited control of industrial institutions on their manpower was another reason to this. This point is relevant in justifying capital excess as well. As a whole, the results of the data envelopment analysis demonstrated that factors out of control of industrial institutions were applied non-optimal. In the other words more autonomy of the institutions in controlling these factors may remove these deficiencies. A comparative analysis of efficient and inefficient years reveals that Iranian industry consumed less inputs and yields more outputs during the efficient years generally. This shows that this section of the economy of the country would deliver more outputs through a better management of resources that result in more contribution in flourishing national economy.

\section{References}

Amann, E. (2002). Globalisation, industrial efficiency and technological sovereignty: Evidence from Brazil. The Quarterly Review of Economics and Finance, 42(5), 875-888.

Charnes, A., Cooper, W. W., Lewin, A. Y., \& Seiford, L. M. (Eds.). (2013). Data envelopment analysis: Theory, methodology, and applications. Springer Science \& Business Media.

Coelli, T. J., Rao, D. S. P., O'Donnell, C. J., \& Battese, G. E. (2005). An introduction to efficiency and productivity analysis. Springer Science \& Business Media.

Fuentes, R., \& Lillo-Bañuls, A. (2015). Smoothed bootstrap Malmquist index based on DEA model to compute productivity of tax offices. Expert Systems with Applications, 42(5), 2442-2450.

Hitomi, K. (2004). Efficiency analysis of Japan's industry and manufacturing. Technovation, 24(9), 741-748.

Jefferson, G. H., Rawski, T. G., \& Zheng, Y. (1996). Chinese industrial productivity: trends, measurement issues, and recent developments. Journal of Comparative Economics, 23(2), 146-180.

Karagiannis, G., \& Lovell, C. K. (2016). Productivity measurement in radial DEA models with a single constant input. European Journal of Operational Research, 251(1), 323-328.

Li, K., \& Lin, B. (2016). Impact of energy conservation policies on the green productivity in China's manufacturing sector: Evidence from a three-stage DEA model. Applied Energy, 168, 351-363.

Norsworthy, J. R., \& Jang, S. L. (1992). Empirical Analysis of Technology and Productivity in High Technology and Service Industries.

Saaty, T. L. (1990). How to make a decision: the analytic hierarchy process. European journal of operational research, 48(1), 9-26.

Statistical Center of Iran, Statistical Yearbook, 1980-2000.

$\mathrm{Wu}, \mathrm{Y}$. (2001). Is China's economic growth sustainable? A productivity analysis. China Economic Review, 11(3), 278-296.

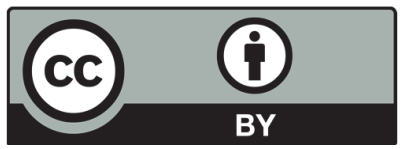

(C) 2017 by the authors; licensee Growing Science, Canada. This is an open access article distributed under the terms and conditions of the Creative Commons Attribution (CC-BY) license (http://creativecommons.org/licenses/by/4.0/). 